\title{
Comparative Nursing Study of Patients Undergoing Coronary Intervention Therapy in Different Ways
}

\author{
Qilian He, Yuquan Luan, Yanfen Fu, Jun Tang* \\ School of Nursing, Dali University, Dali, China \\ Email: jiabei2319@163.com, ${ }^{\star} 1660870619 @ q q . c o m$
}

How to cite this paper: He, Q.L., Luan, Y.Q., Fu, Y.F. and Tang, J. (2019) Comparative Nursing Study of Patients Undergoing Coronary Intervention Therapy in Different Ways. Journal of Biosciences and Medicines, 7, 203-212.

https://doi.org/10.4236/jbm.2019.75022

Received: April 25, 2019

Accepted: May 28, 2019

Published: May 31, 2019

\begin{abstract}
Purpose: To compare the surgical indicators, perioperative complications and postoperative psychological status of patients with coronary interventional therapy (CIT) by radical artery and femoral artery puncture approaches. Methods: 120 patients with CIT were divided into femoral artery group (FAG) and radial artery group (RAG) according to the operation ways. The interventional operation was performed by the same surgeon team and methods. Data of surgical indicators and perioperative complications were recorded and collected. The psychological questionare survey was made within 48 hours the after surgery by the hospital anxiety and depression scale (HAD), and the results were scored by the psychiatrist. Results: The age, sex, ethnicity, education level, disease type, and combined diseases of the two groups had homogeneity without statistical difference. There was no obvious difference in X-ray exposure time, contrast agent usage and operation time in two ways $(P>0.05)$. The success rate of one-time catheterization was higher in FAG than in RAG $(\mathrm{P}<0.05)$. However, the incidence of vascular complications such as subcutaneous hematoma, puncture site bleeding in RAG were significantly lower than those in FAG $(P<0.05)$. Complications of vascular and puncture site bleeding, the operative limb braking time and hospitalization time were longer in FAG than those in the RAG $(\mathrm{P}<0.05)$. The postoperative anxiety and depression question are data analysis showed patients in both groups had obvious higher anxiety and depression scores compare to Chinese norm. Even though there was no difference on anxiety scores of the patients in two groups, but the depression scores showed that patients in the FAG were more prone to psychological depression than patients in the RAG. Combined with the clinical nursing requirements, the postoperative nursing record charts of patients with CIT were established according to general patient data and physical discomfort with high incidence in the above survey
\end{abstract}


results. Conclusion: CIT via radial artery can reduce the incidence of postoperative complications, postoperative physical discomfort and psychological problems such as anxiety and depression of patients.

\section{Keywords}

Nursing, Coronary Interventional Therapy (CIT), Coronary Arterial Angiography (CAG), Percutaneous Coronary Intervention (PCI), Radical Artery, Femoral Artery, The Hospital Anxiety and Depression Scale (HAD)

\section{Introduction}

Coronary heart disease (CHD), as the short for coronary atherosclerotic heart disease, is a common multiple heart disease with the high morbidity and mortality world widely. It mainly refers to a series of symptoms such as myocardial hypoxia, ischemia, necrosis, etc. caused by the occurrence of atherosclerotic lesions in the patient's coronary vessels [1] [2]. At present, in clinical treatment of coronary heart disease, in addition to drug treatment, Coronary arterial angiography (CAG) and percutaneous coronary intervention (PCI) have become the important methods for the diagnosis and treatment of CHD [3]. The traditional path of coronary interventional therapy (CIT) is the femoral artery, but the radial artery method is getting more popular for its advantages as unrestricted patient activity, quick recovery, convenient hemostasis, etc. [4]. Meanwhile, after an acute cardiac event, many patients experience emotional disturbance, which is a normal response to the acute heart event and to hospitalization, but, if not treated with emotive and social support, the symptoms can evolve, resulting in emotional and behavioral disorders [5]. Studies have shown that patients with coronary interventions have more severe psychological stress and anxiety-based emotional disorders, and the psychological state of patients is closely related to the occurrence of surgical accidents and complications [6] [7]. Thus, this study was planned to compare the outcomes and psychological status of patients via two access ways of CIT to provide reference for clinical health guidance and psychological intervention.

\section{Materials and Methods}

\subsection{Materials}

\subsubsection{Sample Collection}

From March 2017 to October 2018, 120 patients underwent coronary angiography in the Department of Cardiology in a provincial hospital were collected as samples. The patients were divided into femoral artery group and radial artery group according to the operation ways. All included patients were suffered an acute cardio disease for the first time. The exclusion criteria were: under age of 18 , the presence of cognitive deficits or dementia, difficulty in comprehending or communicating, and with experiences of a previous acute cardiac event. 


\subsubsection{Radial Artery Group (RAG)}

70 cases were collected with the criteria below. The inclusion criteria were: radial artery pulsation is good, Allen Test is positive (The surgeon uses both hands to simultaneously compress the patient's radial artery and ulnar artery, allowing the patient to repeatedly grip and relax for 10 - 30 seconds, then release the supression of ulnar artery, and the blood circulation could returned to normal within 10 - 15 seconds). Exclusion criteria: negative Allen Test, collateral circulation abnormalities; with upper extremity arterial occlusive disease, radial artery without pulsation or weak; with transplanted bypass vessel; hemodynamic instability, intraoperative aortic ball may be needed during surgery.

\subsubsection{Femoral Artery Group (FAG)}

50 cases were collected with the criteria below. Inclusion criteria: femoral artery pulsation is good. Exclusion criteria: hemodynamic instability; cardiac dysfunction has not been completely corrected; the hip joint cannot be straight cause of the various reasons; Lower limb arterial and venous thrombosis.

\subsection{Methods}

\subsubsection{Interventional Therapy and Methods}

In addition to the access device, the balloon-forming and stent-guided catheters and the types of configurations of the two groups were same or similar. The interventional operation was performed by the same surgeon team and methods. Total operation time, intraoperative $\mathrm{X}$-ray exposure time, puncture site complications, operation success rate, bed rest time and hospital stay days and other information were recorded and collected by the researchers.

\subsubsection{Psychological Questionare Survey}

The Psychological questioners were reedited from the popular and well-recognized question are "The hospital anxiety and depression scale (HAD)" with the uniformal instructional guidance, and filled within 48 hours after surgery by the designed researchers, and the results were scored by the psychiatrist.

\subsection{Statistical Analysis}

The SPSS18.0 statistical software package was used. The measurement data was analyzed by two-sample $\mathrm{T}$ test and the count data was tested by Chi-square test. The difference was defined as $\mathrm{P}<0.05$.

\section{Results}

\subsection{Comparison of the Basic Situation between the Two Groups}

The age, sex, ethnicity, education level, CHD type, and combined diseases of the two groups were analyzed. The data showed there was no significant difference on these indexes between the two groups (Table 1). Age data of $62.67 \pm 10.13$ years old in the RAG and $61.26 \pm 11.57$ years old in the FAG showed no difference in age between the two groups $(t=0.71, p=0.12)$. 
Table 1. Baseline data analysis table for patients with two routes.

\begin{tabular}{|c|c|c|c|c|c|}
\hline Index & & RAG:N (\%) & FAG: N (\%) & $\begin{array}{c}x^{2} \\
\text { value }\end{array}$ & $\begin{array}{c}\mathrm{P} \\
\text { value }\end{array}$ \\
\hline \multirow{7}{*}{$\begin{array}{c}\text { Education } \\
\text { level }\end{array}$} & uneducated & $3(4.29)$ & $1(2.00)$ & \multirow{7}{*}{10.46} & \multirow{7}{*}{0.10} \\
\hline & Primary school & $10(14.29)$ & $15(30.00)$ & & \\
\hline & Middle school & $26(37.14)$ & $11(22.00)$ & & \\
\hline & High school & $8(11.43)$ & $12(24.00)$ & & \\
\hline & Secondary school & $12(17.14)$ & $6(12.00)$ & & \\
\hline & diploma & $4(5.71)$ & $3(6.00)$ & & \\
\hline & bachelor & $7(10.00)$ & $2(4.00)$ & & \\
\hline \multirow{2}{*}{ Sex } & male & $44(62.86)$ & $32(64.00)$ & \multirow{2}{*}{0.02} & \multirow{2}{*}{0.90} \\
\hline & female & $26(37.14)$ & $18(36.00)$ & & \\
\hline \multirow{5}{*}{ CHD type } & Stable angina & $10(14.29)$ & $8(16.00)$ & \multirow{5}{*}{1.97} & \multirow{5}{*}{0.74} \\
\hline & Unstable angina & $10(14.29)$ & $7(14.00)$ & & \\
\hline & $\begin{array}{c}\text { Ischemic } \\
\text { cardiomyopathy }\end{array}$ & $8(11.43)$ & $4(8.00)$ & & \\
\hline & $\begin{array}{l}\text { Acute myocardial } \\
\text { infarction }\end{array}$ & $30(42.86)$ & $26(52.00)$ & & \\
\hline & $\begin{array}{l}\text { silent myocardial } \\
\text { ischemia }\end{array}$ & $12(17.13)$ & $5(10.00)$ & & \\
\hline \multirow{2}{*}{ Ethnicity } & Han Chinese & 64 (91.43) & $45(90.00)$ & \multirow{2}{*}{0.00} & \multirow{2}{*}{1.00} \\
\hline & Ethnic Chinese & $6(8.57)$ & $5(10.00)$ & & \\
\hline \multirow{2}{*}{$\begin{array}{l}\text { Combined } \\
\text { diseases }\end{array}$} & With & $55(78.57)$ & $35(75.00)$ & \multirow{2}{*}{1.14} & \multirow{2}{*}{0.29} \\
\hline & without & $15(21.43)$ & $15(25.00)$ & & \\
\hline
\end{tabular}

\subsection{Comparison of Surgical Related Indicators with Two Routes}

\subsubsection{One-Time Tube Success Rate}

The tubes of 83 cases in RAG were successfully placed in one time, and 7 cases were changed into femoral artery puncture after failure of radial artery puncture. Therefore, the success rate of one-time puncture of the RAG was $90.91 \%$. 70 patients in the FAG were successfully punctured with the 1st time puncture success rate of $100.00 \%$. The results showed the success rate of FAG was higher than that of the RAG (Table 2).

\subsubsection{X-Ray Exposure Time}

The intraoperative X-ray exposure time of the patients in the two groups was compared and analyzed. Because the data of two groups were not normally distributed, the Rank Sum Test was used and showed no significant difference The median time of the radial artery irradiation in RAG was 6 minutes, and the interquartile range was 3 - 11 minutes. The median time of irradiation in the FAG was 5 minutes, and the interquartile range was $3-7$ minutes (Table 3 ).

\subsubsection{Other Surgical Related Indicators of Patients with Two Routes}

The operation time, postoperative limb braking time, hospitalization time, and 
Table 2. One-time tube success rate of two routes.

\begin{tabular}{ccccc}
\hline Group & success & failure & $x^{2}$ value & P value \\
\hline RAG & 70 & 7 & 4.15 & 0.04 \\
FAG & 43 & 0 & & \\
\hline
\end{tabular}

Table 3. Intraoperative X-ray exposure time of two groups of patients.

\begin{tabular}{cccc}
\hline Group & $\mathrm{M}(\mathrm{Q} 25 \sim \mathrm{Q} 75)$ & Rank Sum Test value & P value \\
\hline RAG & $6(3-11)$ & 1275.00 & 0.11 \\
FAG & $5(3-7)$ & & \\
\hline
\end{tabular}

contrast agent usage were statistically analyzed. The results showed that there was no statistical difference on the operation time and the contrast agent usage in the two paths. However, the postoperative limb braking time and hospital stay days were significantly shorter in the RAG than in the FAG $(\mathrm{P}<0.05$, Table 4$)$.

\subsubsection{Comparison of Perioperative Complications in Patients with Two Routes}

The intraoperative and postoperative complications of patients with two routes were compared. The results showed that there were significant differences in postoperative complications on subcutaneous hematoma and puncture site bleeding $(\mathrm{P}=0.04)$. No significant differences were shown on the other perioperative complications (Table 5 and Table 6).

\subsubsection{Postoperative Psychological Status of Patients with Two Routes}

The postoperative anxiety and depression question are data analysis showed patients in both groups had obvious higher anxiety and depression scores compare to Chinese norm, Which implys all patients had different levels of emotional pressure. Even though there was no difference on anxiety scores of the patients in two groups, but the depression scores showed that patients in the FAG were more prone to psychological depression than patients in the RAG $(\mathrm{P}<0.05$, Table 7).

\subsubsection{Postoperative Physical Discomfort Situations of Patients with Two Routes}

The results of postoperative physical discomfort of patients with two routes showed differences in postoperative symptoms such as low back pain, poor night sleep, decreased appetite, abdominal distension, urinary retention, constipation, and numbness of the limbs $(\mathrm{P}<0.05)$. Patients inRAG were less likely to have those postoperative physical discomfort than patients inFAG (Table 8).

\subsubsection{Developing a Postoperative Nursing Recordchart}

Combined with the clinical nursing requirements, the postoperative nursing record charts of patients with CIT were established according to general patient data and physical discomfort with high incidence in the above survey results (Table 9). 
Table 4. Comparison of other surgical related indicators in patients with two routes.

\begin{tabular}{ccccc}
\hline Index & RAG $(\bar{x} \pm s)$ & FAG $(\bar{x} \pm s)$ & $\begin{array}{c}\text { T } \\
\text { value }\end{array}$ & $\begin{array}{c}\text { P } \\
\text { value }\end{array}$ \\
\hline $\begin{array}{c}\text { operation time (mins) } \\
\text { postoperative limb braking } \\
\text { time (hours) }\end{array}$ & $46.67 \pm 33.28$ & $38.58 \pm 21.43$ & 1.62 & 0.11 \\
$\begin{array}{c}\text { hospitalization time (days) } \\
\text { contrast agent usage (ml) }\end{array}$ & $13.14 \pm 10.25$ & $27.80 \pm 8.93$ & -3.14 & 0.00 \\
& $137.37 \pm 87.27$ & $119.84 \pm 8.20$ & -3.85 & 0.00 \\
\hline
\end{tabular}

Table 5. Comparison of complications (intraoperative) between the two groups.

\begin{tabular}{|c|c|c|c|c|c|}
\hline complications & appearance & RAG.N (\%) & FAG.N (\%) & $x^{2}$ value & $P$ value \\
\hline \multirow{2}{*}{ Puncture artery fistula } & with & $9(12.86)$ & $2(4.00)$ & \multirow{2}{*}{1.79} & \multirow{2}{*}{0.18} \\
\hline & without & $61(87.14)$ & $48(96.000)$ & & \\
\hline \multirow{2}{*}{ Coronary arteryfistula } & with & $2(2.86)$ & $0(0.00)$ & \multirow{2}{*}{0.23} & \multirow{2}{*}{0.63} \\
\hline & without & $68(97.14)$ & $50(100.00)$ & & \\
\hline \multirow{2}{*}{ Vascular vagus reflex } & with & $2(2.86)$ & $0(0.00)$ & \multirow{2}{*}{0.23} & \multirow{2}{*}{0.63} \\
\hline & without & $68(97.14)$ & $50(100.00)$ & & \\
\hline \multirow{2}{*}{$\begin{array}{l}\text { Gastrointestinal } \\
\text { reaction }\end{array}$} & with & $1(1.43)$ & $0(0.00)$ & \multirow{2}{*}{0.00} & \multirow{2}{*}{1.00} \\
\hline & without & $69(98.57)$ & $50(100.00)$ & & \\
\hline \multirow{2}{*}{$\begin{array}{l}\text { Contrast agent } \\
\text { response }\end{array}$} & with & $2(2.86)$ & $0(0.00)$ & \multirow{2}{*}{0.23} & \multirow{2}{*}{0.63} \\
\hline & without & 68 (97.14) & $50(100.00)$ & & \\
\hline
\end{tabular}

Table 6. Comparison of complications (postoperative) between the two groups.

\begin{tabular}{|c|c|c|c|c|c|}
\hline complications & occurance & RAG.N (\%) & FAG.N (\%) & $x^{2}$ value & $P$ value \\
\hline \multirow{2}{*}{ Vascular vagus reflex } & with & $2(2.86)$ & $2(4.00)$ & \multirow{2}{*}{0.00} & \multirow{2}{*}{1.00} \\
\hline & without & $68(97.14)$ & $48(96.00)$ & & \\
\hline \multirow{2}{*}{ Arrhythmia } & with & $3(4.29)$ & $0(0.00)$ & \multirow{2}{*}{0.79} & \multirow{2}{*}{0.37} \\
\hline & without & $67(95.71)$ & $50(100.00)$ & & \\
\hline \multirow{2}{*}{ Puncture site bleeding } & with & $6(8.57)$ & $11(22.00)$ & \multirow{2}{*}{4.33} & \multirow{2}{*}{0.04} \\
\hline & without & $64(91.43)$ & $39(78.00)$ & & \\
\hline \multirow{2}{*}{$\begin{array}{c}\text { Subcutaneous } \\
\text { hematoma }\end{array}$} & with & $5(7.14)$ & $10(20.00)$ & \multirow{2}{*}{4.41} & \multirow{2}{*}{0.04} \\
\hline & without & $65(92.86)$ & $40(80.00)$ & & \\
\hline \multirow{2}{*}{$\begin{array}{l}\text { Gastrointestinal } \\
\text { reaction }\end{array}$} & with & $1(1.43)$ & $3(6.00)$ & \multirow{2}{*}{0.74} & \multirow{2}{*}{0.39} \\
\hline & without & $69(98.57)$ & $47(94.00)$ & & \\
\hline
\end{tabular}

Table 7. Postoperative anxiety and depression scores between the two groups.

\begin{tabular}{cccc}
\hline Group & N & anxiety scores & depression scores \\
\hline RAG & 70 & $10.03 \pm 2.41$ & $9.17 \pm 3.04$ \\
FAG & 50 & $9.28 \pm 2.31$ & $11.64 \pm 2.33$ \\
T value & & 1.72 & -5.04 \\
P value & 0.09 & 0.00 \\
\hline
\end{tabular}


Table 8. Postoperative physical discomfort in patients with two routes.

\begin{tabular}{|c|c|c|c|c|c|}
\hline $\begin{array}{l}\text { physical } \\
\text { discomfort }\end{array}$ & occurance & RAG.N(\%) & FAG.N(\%) & $x^{2}$ value & $P$ value \\
\hline \multirow[b]{2}{*}{ back pain } & with & $10(20.00)$ & $17(34.00)$ & \multirow[b]{2}{*}{6.50} & \multirow[b]{2}{*}{0.01} \\
\hline & without & $60(80.00)$ & $33(66.00)$ & & \\
\hline \multirow[b]{2}{*}{ poor night sleep } & with & $12(17.14)$ & $18(36.00)$ & \multirow[b]{2}{*}{5.53} & \multirow[b]{2}{*}{0.02} \\
\hline & without & $58(82.86)$ & $32(64.00)$ & & \\
\hline \multirow{2}{*}{ decreased appetite } & with & $5(7.14)$ & $10(20.00)$ & \multirow{2}{*}{4.41} & \multirow{2}{*}{0.04} \\
\hline & without & $65(92.86)$ & $40(80.00)$ & & \\
\hline \multirow{2}{*}{$\begin{array}{l}\text { abdominal } \\
\text { distension }\end{array}$} & with & $6(8.57)$ & $11(22.00)$ & \multirow{2}{*}{4.33} & \multirow{2}{*}{0.04} \\
\hline & without & 64 (91.43) & $39(78.00)$ & & \\
\hline \multirow{2}{*}{ urinary retention } & with & $1(1.43)$ & $10(20.00)$ & \multirow[b]{2}{*}{9.78} & \multirow{2}{*}{0.00} \\
\hline & without & 69 (98.57) & $40(80.00)$ & & \\
\hline \multirow{2}{*}{ constipation } & with & $6(8.57)$ & $11(22.00)$ & \multirow{2}{*}{4.33} & \multirow{2}{*}{0.04} \\
\hline & without & 64 (91.43) & $39(78.00)$ & & \\
\hline \multirow{3}{*}{ numbness of the limbs } & with & $1(1.43)$ & $10(20.00)$ & \multirow{3}{*}{9.78} & \multirow{3}{*}{0.00} \\
\hline & without & $69(98.57)$ & $40(80.00)$ & & \\
\hline & with & $67(95.71)$ & $50(100.00)$ & & \\
\hline
\end{tabular}

Table 9. Postoperative nursing record chart of patients with CIT.

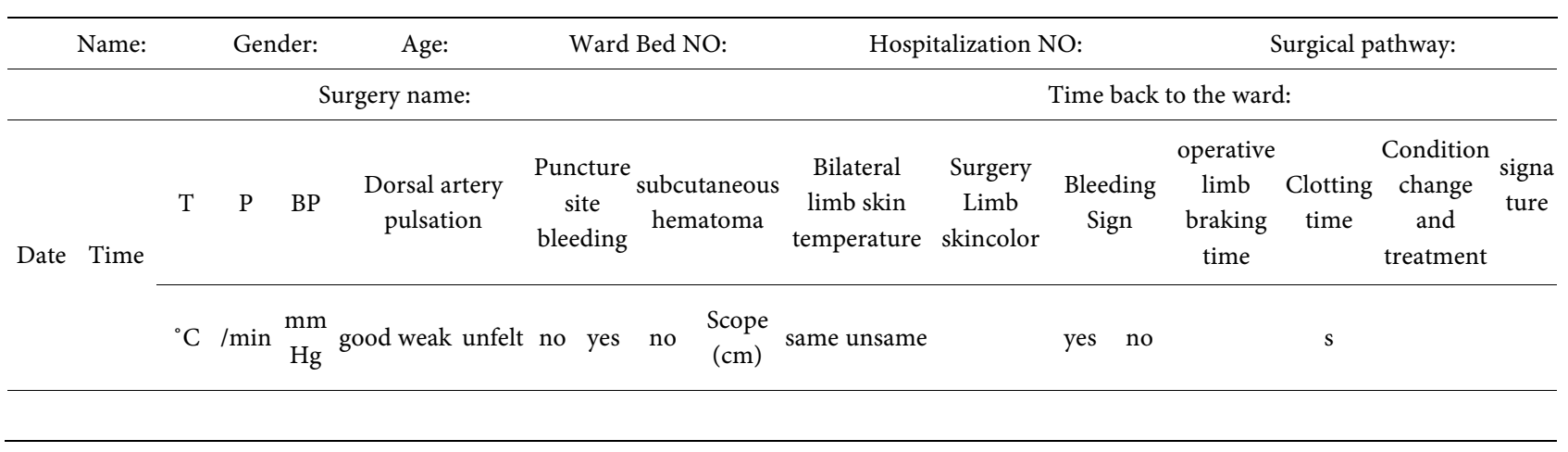

\section{Discussion}

This study compared and analyzed the surgical indicators, perioperative complications and postoperative psychological status of CIT by two puncture approaches. The results showed that there was no obvious difference in X-ray exposure time, contrast agent usage and operation time in two ways $(\mathrm{P}>0.05)$. The success rate of one-time catheterization was higher in femoral artery way than in radial artery way $(\mathrm{P}<0.05)$. However, the incidence of vascular complications CIT such as subcutaneous hematoma, puncture site bleeding via radial artery route was significantly lower than that via femoral artery route $(\mathrm{P}<0.05)$, indicating that due to the superficial position of the radial artery, no adjacent important veins and nerves around, and good collateral circulation between the 
radial artery and ulnar artery, radial artery puncture is safer and easier to perform postoperative hemostasis. Complications of vascular and puncture site bleeding, the operative limb braking time and hospitalization time were longer in FAG than those in the RAG $(\mathrm{P}<0.05)$. The above findings are consistent with a number of domestic and foreign studies including meta-analysis [8] [9] [10] [11] [12]. Besides, the postoperative psychological status question are survey showed that patients in the FAG were more prone to psychological depression than patients in the RAG $(P<0.05)$. And the patents in FAG has more complaints of postoperative symptoms such as low back pain, poor night sleep, decreased appetite, abdominal distension, urinary retention, constipation, and numbness of the limbs $(\mathrm{P}<0.05)$. The nursing care record chart of patients after CIT established according to our survey results targeted on the two surgery ways of CIT, which could provide a practical reference and guidance for clinical nursing work.

Acute cardiac patients can experience different emotions, like shock, low or fluctuating moods, sadness, worry, guilt, and anger; mood changes are displayed by tiredness, irritability, tearfulness, loss of pleasure in usual activities, withdrawal from others, sleep disturbance, and changes in appetite and sex drive [13] [14]. There are also disturbances of the social field, like reduced self-esteem, concerns about role changes, and pessimism about the future [15]. This distress is considered a normal response to loss and to increased awareness of mortality; frequently, it has a spontaneous resolution within a few months, but some patients present a negative evolution of these conditions, developing anxiety disorders and major depression [16].

As our results showed, patients of the CIT had experienced obvious anxiety and depression no matter via radical artery or femoral artery way. People who suffer from a cardiovascular event often do not receive adequate information about care continuation, rehabilitation, the chronic condition that affects them, and the need to change their eating and behavioral habits to prevent complications and to improve their quality of life [17].

Currently, health professionals have basic notions on the principles of the helping and human relations. The most specialized training, as a counselor, is the result of personal interest and not part of basic training. For health professionals, the emotional recovery of the cardiac patient has to be considered as central care element. Personalizing the treatment and making the patient really part of the care process is necessary to encourage a conscious change [18]. To address this need, our future research will develop relational tools for nurses, with the purpose of leading the patient towards a better quality of life and supporting the patient in this moment of fragility, and guarantees uniformity of care and simplifies the insertion of new professionals in the team when necessary.

\section{Acknowledgements}

The authors thank Yanhua Ma, Huanping Gu, Cao Xing for their help of the researches. Great thanks to Bing Li for his professional help of the data analysis. 


\section{Conflicts of Interest}

The authors declare no conflicts of interest regarding the publication of this paper.

\section{References}

[1] Thompson, K.A., Philip, K.J., Barbagelata, A. and Schwarz, E.R. (2010) The New Concept of Interventional Heart Failure Therapy: Electrical Therapy, Treatment of CAD, Fluid Removal, and Ventricular Support. J Cardiovasc Pharmacol Ther., 15, 102-111. https://doi.org/10.1177/1074248410366447

[2] Lassen, J.F., Burzotta, F., Banning, A.P., et al. (2018) Percutaneous Coronary Intervention for the Left Main Stem and Other Bifurcation Lesions: 12th Consensus Document from the European Bifurcation Club. EuroIntervention., 13, 1540-1553. https://doi.org/10.4244/EIJ-D-17-00622

[3] Grines, C.L., Harjai, K.J. and Schreiber, T.L. (2015) Percutaneous Coronary Intervention: 2015 in Review. JInterv Cardiol., 29, 11-26. https://doi.org/10.1111/joic.12272

[4] Capodanno, D. (2016) Risk Stratification for Percutaneous Coronary Intervention. Interv Cardiol Clin., 5, 249-257. https://doi.org/10.1016/j.iccl.2015.12.009

[5] Qi, G., Sun, Q., Xia, Y. and Wei, L. (2017) Emergency Percutaneous Coronary Intervention through the Left Radial Artery Is Associated with Less Vascular Complications than Emergency Percutaneous Coronary Intervention through the Femoral Artery. Clinics, 72, 1-4. https://doi.org/10.6061/clinics/2017(01)01

[6] Mitchell, J.D. and Brown, D.L. (2016) Update on Percutaneous Coronary Intervention in Stable Coronary Artery Disease. JAMA Intern Med., 176, 1855-1856. https://doi.org/10.1001/jamainternmed.2016.6656

[7] Rao, G., Sheth, S. and Grines, C. (2018) Percutaneous Coronary Intervention: 2017 in Review. J Interv Cardiol., 31, 117-128. https://doi.org/10.1111/joic.12508

[8] Bhatt, D.L. (2018) Percutaneous Coronary Intervention in 2018. JAMA, 319, 2127-2128. https://doi.org/10.1001/jama.2018.5281

[9] Xie, H.P. and Tan, A.M. (2017) Nursing Care of Coronary Angiography and Stent Implantation through Radial Artery. Hebei Medicine, 15, 108-109.

[10] Li, Y.Q. (2017) Nursing Experience of Coronary Intervention through Two Different Routes: Radial Artery and Femoral Artery. Chinese Public Health Medicine, 12, 171-174.

[11] Duan, J.H. (2015) Coronary Intervention Was Performed through Two Different Routes: Radial Artery and Femoral Artery. Knowledge of Cardiovascular Disease Prevention, 119-120.

[12] Lu, W.L. and Su, W.P. (2017) Comparative Study of Local Complications after Coronary Intervention via Radial Artery and Brachial Artery. Nursing Practice and Research, 6, 11-13.

[13] Xin, X. (2016) Clinical Nursing of 64 Cases of Coronary Intervention via Radial Artery. Qilu Journal of Nursing, 14, 102.

[14] Wang, X.K., Wang, X.L. and Jiang, S.L. (2018) Clinical Observation of 180 Cases Treated by Coronary Angiography and Interventional Therapy via Radial Artery. Hebei Medical Science, 16, 8-10.

[15] Dai, L.Q. and Huang, L.Y. (2017) Comparison of the Effects of Coronary Intervention by Two Different Approaches. Qilu Journal of Nursing, 17, 31-32. 
[16] Murphy, B.M., Higgins, R.O. and Jackson, A.C. (2015) Patients Want to Know about the "Cardiac Blues". Australian Family Physician, 44, 826-832.

[17] Pryor, T., Page, K., Patsamanis, H. and Jolly, K.A. (2014) Investigating Support Needs for People Living with Heart Disease. Journal of Clinical Nursing, 23, 166-172. https://doi.org/10.1111/jocn.12165

[18] Murphy, B.M., Higgins, R.O., Shand, L., Page, K., Le Grande, M.R. and Jackson, A.C. (2016) Improving Health Professionals' Self-Efficacy to Support Cardiac Patients' Emotional Recovery: The "Cardiac Blues Project". European Journal of Cardiovascular Nursing, 16, 1-7. https://doi.org/10.1177/1474515116643869 